\title{
Measurement of reactor core temperature using multispectral infrared pyrometry in accidental conditions
}

\author{
A.Ladaci*, G. Cheymol, H. Maskrot, C. Destouches, L. Ferry, and C. Gonnier \\ * Den - Service d'Etudes Analytiques et de Réactivité des Surfaces (SEARS), CEA \\ Ayoub.ladaci@cea.fr
}

$\mathrm{T}^{\mathrm{s}}$ he Loss Of Coolant Accident (LOCA) is one of the most considered accidental scenario in nuclear power plant design [1]. It occurs after a break of the primary circuit, which leads to a strong pressure decrease inducing an overheating of the full cladding. The oxidation due to water steam and high temperature undermines the claddings and can lead to their burst with the release of fission products [2]. To simulate such accident, the Light-water One Rod Equipment for LOCA Experimental Investigations (LORELEI) test device will be implemented in the Jules Horowitz research reactor at the CEA Cadarache centre [3]. It will allow the study of full claddings behaviours under such conditions [4]. The cladding surface temperature monitoring is essential in this experiment; it allows linking the burst conditions with the temperature. However, this measurement needs to be non-invasive in order to minimize the perturbation and avoiding any change of the burst conditions, which exclude the use of thermocouples. In this case, the Pyrometry based temperature measurement techniques presents a suitable solution [5].

The aim of this work is to develop a non-contact temperature measurement technique allowing the monitoring of the full cladding temperature during a LOCA. In order to achieve that, we developed an infrared optical multispectral pyrometry-based system. This technique presents a good solution allowing to reach the required temperature range, accuracy and acquisition speed $\left(700-1200{ }^{\circ} \mathrm{C},>10\right.$ ${ }^{\circ} \mathrm{C}$ and $>10 \mathrm{~Hz}$, respectively). The multispectral analysis allows us to measure both emissivity and temperature by using a calibrated black body source as a reference. The device transfer function is

A. LADACI, G. Cheymol and H. Maskrot are with the Den - Service d'Etudes Analytiques et de Réactivité des Surfaces (SEARS), CEA, Université Paris-Saclay, F-91191, Gif sur Yvette, France (corresponding author: guy.cheymol@cea.fr).

C. Destouches is with the Den - Service de Physique Expérimentale (SPEX/LDCI), CEA, F-13108, St Paul lez Durance, France. obtained by a direct comparison between the theoretical black body spectrum and one measured on the black body source. The emissivity is considered quite flat on our working spectral range $(1-1.6 \mu \mathrm{m})$ as it was demonstrated in previous works [6].

However, a main issue of this technique is the optical system weakness to the reactor core extremes conditions during the accident (high temperature, radiation flux and hydrogen emission) [7]. Indeed, the multispectral pyrometry measurement is very sensitive to the system spectral losses variations, which can be produced by the Radiation Induced Attenuation (RIA) due to the high gamma and neutron fluxes [8]. In order to avoid such issue, we used radiation-hardened materials such as diamond and pure silica glass [9]. The choice of these materials is based on the CEA expertise in developing optical devices for harsh environment. However, the device prototype has to be tested under those new extreme conditions in order to be qualified before its integration in the LORELEI device.

In this paper, we study the water steam influence on the temperature measurement using a prototype of the IR multispectral pyrometer on the EDGAR facility of the CEA (Figure 1.a and b.). The EDGAR facility allows the cladding ohmic heating up to $1200^{\circ} \mathrm{C}$, with a temperature monitoring using an internal thermocouple in addition to a commercial optical monochromatic pyrometer [10]. The atmosphere can be switched from air to water vapor using a steam generator. This allows to validate the reliability of the system under the reactor accidental atmosphere where high steam flows are expected.

L. Ferry is with the Den - Service Réacteur Jules Horowitz (SRJH/LEDI), F-13108, St Paul lez Durance, France.

C. Gonnier is with the Den - Service Réacteur Jules Horowitz (SRJH), F13108, St Paul lez Durance, France. 


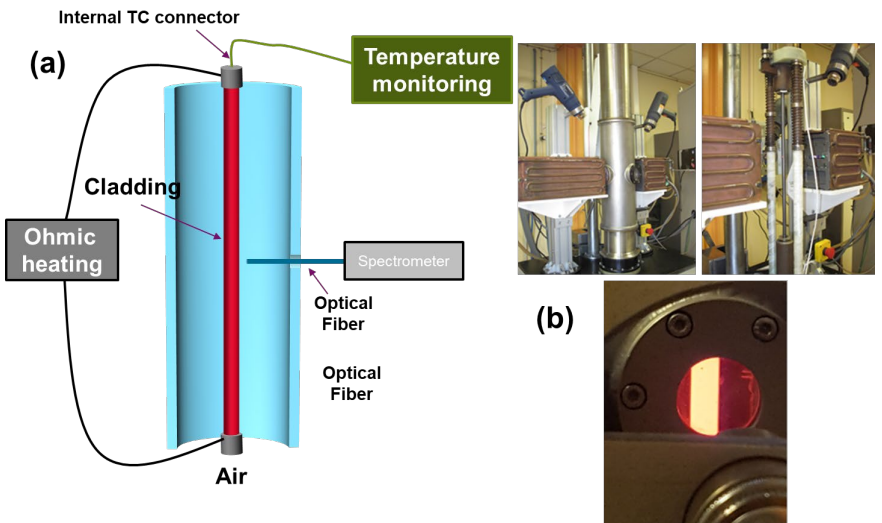

Figure 1.a Experimental setup for steam effect testing on the temperature measurement by IR pyrometry, b. Pictures of EDGAR test facility

The steam flows affect the measurement accuracy by introducing additional spectral losses to the signal acquisition chain; this attenuation will induce an important disturbance in a spectral band at about 1.38 $\mu \mathrm{m}$, which will decrease the temperature measurement accuracy. In order to avoid such issue, this absorption band was removed from the tested spectral range; in this case, the measurements are performed on a [1-1.3 $\mu \mathrm{m}]$ spectral range.

The measured temperatures in air and steam environments using IR pyrometry are reported in Figure 2.

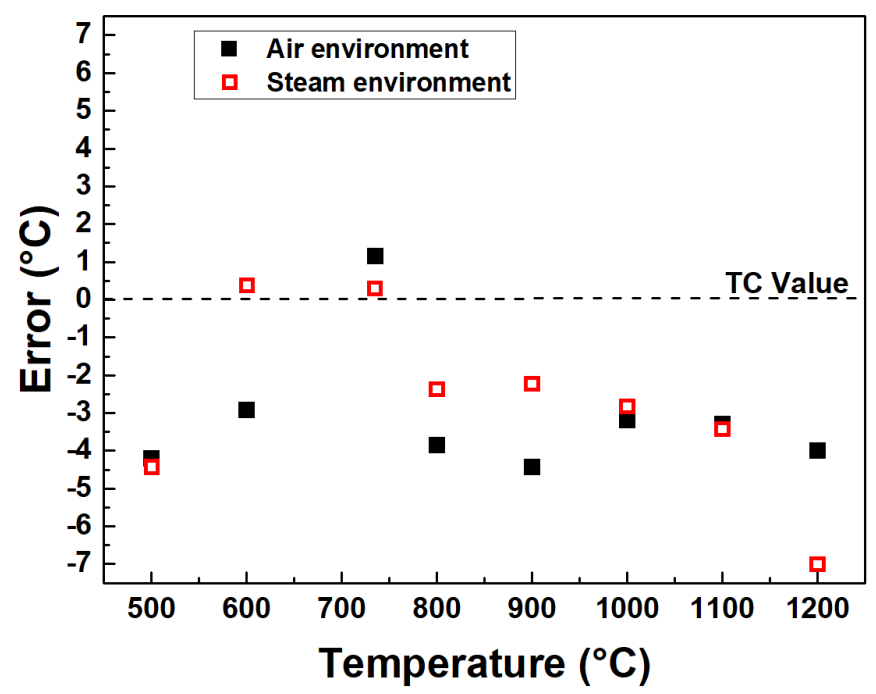

Figure 2. Temperature values measured in air (black marks) and steam (red marks) environments compared to internal thermocouple values (red dash line) on Zircaloy-4 cladding

In both cases, the temperature is estimated with a good accuracy compare to the TC values, using the multispectral pyrometry in an adapted spectral range.
The uncertainty of the system remains less than $1 \%$ for both air and steam environments.

\section{ACKNOWLEDGMENTS}

The authors are thankful to LC2M laboratory for providing the cladding samples; and in particular, to Q. Houmaire and M. Dumerval for their help during the EDGAR experiments.

\section{REFERENCES}

[1] K.A. Terrani, D. Wang, L.J. Ott, R.O. Montgomery, 'The effect of fuel thermal conductivity on the behavior of LWR cores during loss-of-coolant accidents', Journal of Nuclear Materials, 448, 13,2014, 512-519.

[2] F. Erbacher, H. Neitzel, H. Rosinger, H. Schmidt, and K. Wiehr, "Burst Criterion of Zircaloy Fuel Claddings in a Loss-of-Coolant Accident," in Zirconium in the Nuclear Industry, ed. D. Franklin (West Conshohocken, PA: ASTM International, 1982, 271-283.

[3] L. Ferry, D. Parrat, C. Gonnier, C. Blandin, Y. Weiss, and A. Sasson, "The LORELEI test device for LOCA experiments in the Jules Horowitz reactor," in WRFPM 2014 conference, Japan, 2014.

[4] F. Erbacher and S. Leistikow, "Zircaloy Fuel Cladding Behavior in a Loss-of-Coolant Accident: A Review," in Zirconium in the Nuclear Industry, ed. R. Adamson and L. S. Van (West Conshohocken, PA: ASTM International, 1987, 451-488.

[5] B. Bouvry, G. Cheymol, L. Ramiandrisoa, B. Javaudin, C. Gallou, H. Maskrot, et al., "Multispectral pyrometry for surface temperature measurement of oxidized Zircaloy claddings," Infrared Physics and Technology, 83, 2017, 78-87.

[6] B. Bouvry , G. Cheymol , C. Gallou, H. Maskrot, C. Destouches, L. Ferry, and C. Gonnier.,'Theoretical and Experimental Analyses of the Impact of High-Temperature Surroundings on the Temperature Estimated by an Optical Pyrometry Technique,' in IEEE Transactions on Nuclear Science, 65, 9, 2018, 2593-2600.

[7] Y. Lee, T. J. McKrell, C. Yue and M. S. Kazimi, 'Safety Assessment of $\mathrm{SiC}$ Cladding Oxidation under Loss-of-Coolant Accident Conditions in Light Water Reactors' Nuclear Technology, $183: 2,210-227$

[8] G. Cheymol, H. Long, J.F. Villard, B. Brichard, "High Level Gamma and Neutron Irradiation of Silica Optical Fibers in CEA OSIRIS Nuclear Reactor" IEEE Trans. Nucl. Sci., 55, 2008, 252-2258.

[9] S. Girard, A. Morana, A. Ladaci, T. Robin, L. Mescia, J.J. Bonnefois, M. Boutillier, J. Mekki, A. Paveau, B. Cadier, E. Marin, Y. Ouerdane, and A. Boukenter, "Recent advances in radiation-hardened fiber-based technologies for space applications", Journal of Optics, 20, 9, 2018, 093001.

[10] T. Forgeron, J. Brachet, F. Barcelo, A. Castaing, J. Hivroz, J. Mardon, and C. Bernaudat, "Experiment and modeling of advanced fuel rod cladding behavior under LOCA conditions: alpha-beta phase transformation kinetics and EDGAR methodology," presented at the Zirconium in the Nuclear Industry: 12th international symposium, 2000. 